\section{An After-school Gardening Club to Promote Fruit and Vegetable Consumption among Fourth Grade Students: The Assessment of Social Cognitive Theory Constructs}

\author{
Suzanne A. O’Brien and Candice A. Shoemaker ${ }^{1}$
}

ADDITIONAL INDEX WORDs. out-of-school time, children's nutrition education, fruit and vegetable preference, self-efficacy, outcome expectations

\begin{abstract}
SuMMARY. An eight-lesson gardening and nutrition curriculum with a hands-on gardening emphasis was taught as an after-school program to determine the effect it had on increasing children's nutrition knowledge, fruit and vegetable preference, and improving children's self-efficacy and outcome expectations for gardening and for consuming fruit and vegetables. Seventeen fourth grade students participated in the experimental group as part of an after-school gardening club, and 21 fourth grade students served as the control group. Nutrition knowledge, preference, self-efficacy, outcome expectations, as well as demographic measures were obtained at baseline and end-program. There were no differences in nutrition knowledge scores between or within groups at baseline or at end-program. However, baseline scores were high ( $>7$ out of 10 possible) for both groups. Both groups indicated a high preference for fruit at baseline and end-program. Vegetable preference did not increase over the course of the program for both groups. At baseline, measurements of gardening self-efficacy and outcome expectations were significantly different between the groups. The experimental group was able to maintain high self-efficacy and outcome expectations scores during the program, but the control group's scores increased significantly for gardening self-efficacy and outcome expectations at the end-program assessment. Further research to clarify aspects of gardening (i.e., season, harvesting, crops grown) that have the greatest impact on influencing preference, self-efficacy and outcome expectations is needed.
\end{abstract}

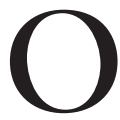
ver the past three decades there has been a general improvement in the health status of American children. However, U.S. children still need to develop healthy eating and physical activity patterns that will help reduce the risk of chronic long-term health problems such as obesity, coronary heart disease, type-2 diabetes, stroke, cancer, and osteoporosis. Healthy eating habits in childhood also help to prevent undernutrition and growth retardation as well as other child nutrition problems such as iron-deficiency anemia and dental caries (Nicklas and Johnson, 2004). Healthy eating habits in chil-

${ }^{1}$ Graduate Student and Associate Professor, respectively, Department of Horticulture, Forestry and Recreation Resources, Kansas State University, 2021 Throckmorton Plant Sciences Center, Manhattan, KS 66506. To whom correspondence requests should be addressed: cshoemak@ksu.edu

Contribution no. 05-80-J of the Kansas Agricultural Experiment Station, Manhattan. This paper is a portion of a master's thesis submitted by S.A. (Poston) O'Brien. The authors thank Marlatt Elementary and Amanda Arnold Elementary schools for their participation in this study, and also all the Master Gardener and student volunteers that helped with this project. dren can best be achieved by eating a variety of foods in moderation as recommended by the new U.S. Department of Agriculture (USDA) Pyramid Plan (USDA, 2005).

Previous USDA Food Guide Pyramid recommendations were that all Americans consume a minimum of two servings of fruit and three servings of vegetables daily, and may now be higher depending on age, gender, and physical activity level (USDA, 2005). Data from the Continuing Survey of Food Intakes by Individuals (CSFII) 1999-2002 show that children age 6 to 11 years are only consuming an average of 1.4 servings of fruit and 2.1 servings of vegetables per day (Cook and Friday, 2004). The percentage of children consuming at least the minimum servings of fruit and vegetables was $25 \%$. The percentage of children who consumed less than one serving of fruit or vegetables per day was $53 \%$ and $33 \%$, respectively (Cook and Friday, 2004).

Schools are consistently being identified as appropriate sites for health education and promotion.
Many multidisciplinary programs have been launched to educate students about the benefits of eating fruit and vegetables (Levine et al., 2002; Perry et al., 1998, 2004; Reniscow et al., 1998). Studies have shown that school gardening can be an effective strategy to increase school children's nutrition knowledge and preferences for fruit and vegetables (Canaris, 1995; Cason, 1999; Lineberger and Zajicek, 2000; Morris and Zidenberg-Cherr, 2002; Morris et al., 2001, 2002). However, the specific amount of time spent gardening has not been reported in the literature on children's gardening and nutrition programs.

Social cognitive theory (SCT) is the most common theory used in successful behavior change programs for children (Lytle and Achterberg, 1995). In 1962 Albert Bandura began developing the beginnings of what is now called SCT, and with help from his collegues, has identified many different constructs in SCT that are important in understanding behavior (Baranowski et al., 1997). Person factors, otherwise known as moderating variables, are an individual's unique aspects that are relevant to behaviors, such as taste preferences, perceived self-efficacy, or outcome expectations (Kirby et al., 1995). Self-efficacy is a judgment of one's ability to organize and execute given types of performances (Bandura, 1997) and has been identified as an important variable in children's behavior change research (Domel et al., 1996; Ryan and Dzewaltowski, 2002). An outcome expectation is a judgment of the likely consequence such performances will produce (Bandura, 1997). These moderating variables are constructs often used in SCT research (Bandura, 1997, 2004; Reynolds et al., 1999). SCT provides a foundation for designing interventions because it establishes a basis for understanding how complex characteristics interact (Kirby et al., 1995).

The objective of this study was to follow eight specific lesson objectives chosen from the Junior Master Gardener: Health and Nutrition from the Garden Curriculum (Genzer et al., 2001 ), with 30 min of gardening time during each lesson to determine if the combination increased children's nutrition knowledge, fruit and vegetable preference, and self-efficacy and outcome expectations for gardening and for consuming fruit and vegetables. 


\section{Methods}

Design and PARTICIPANTS. This study was quasi-experimental with baseline and end-program measurements. Participants were directly recruited from two elementary schools in Manhattan, Kans. At the experimental school, 17 fourth grade students participated in an after-school gardening club for 10 weeks, and baseline data and end-program measurements were obtained during the first and last meeting of the garden club. A class of 21 fourth grade students from a different, but similar elementary school, served as the control group for this study. Baseline and end-program measurements were taken about 6 weeks apart for this group in cooperation with the classroom teacher's availability. Fourth grade students were the targeted audience for this study because the chosen curriculum, Junior Master Gardener: Health and Nutrition from the Garden (Genzer et al., 2001), was developed and tested for this cohort.

Curriculum. The curriculum for this study was eight lessons selected from the Junior Master Gardener: Health and Nutrition from the Garden (Genzer et al., 2001) program that reflected a balance between gardening and nutrition lessons. Program objectives of each lesson were followed closely. Weekly lessons and objectives can be found in Table 1.

Program Delivery. The weekly program consisted of three parts: each week children were served a healthy fruit or vegetable snack, taught the lesson, and participated in $30 \mathrm{~min}$ of gardening. Total program time available each week was $80 \mathrm{~min}$, and the full program time was utilized each week. The study began in mid-March and ended in late May 2004.

Volunteer help was recruited by the researchers for this study. Three Master Gardeners, two university students, and two researchers attended each session. Master Gardener and student volunteers facilitated and led small groups during the lessons, as well as helped supervise proper gardening techniques during the gardening portion of the lessons. All program lessons were led by one researcher while documentation of the lesson and behind-the-scenes preparation were done by the second researcher.

Measures. In this study the variables that were measured were nutrition knowledge, fruit and vegetable preference (Cronbach's alpha $=0.18$ and 0.55 , respectively), self-efficacy for gardening (alpha $=0.81$ ) and for fruit and vegetable consumption (alpha $=$ 0.28 ), and outcome expectations for gardening ( alpha $=0.71)$ and for fruit and vegetable consumption (alpha $=$ $0.67)$.

Nutrition knowledge was assessed on a variety of general nutrition topics with a 10-item questionnaire in multiple choice and true/false formats (see Table 4 for examples). Questions were derived from the Family Nutrition Program (FNP) standard program evaluation questionnaire for students in grades 3-6 (FNP, 2003), a research instrument with similar outcome mea-

Table 1. Selected lessons and objectives from the Junior Master Gardener: Health and Nutrition from the Garden (Genzer et al., 2001) curriculum used in a 10week after-school gardening and nutrition program.

\begin{tabular}{|c|c|}
\hline Lesson name & Objective \\
\hline Plant Needs & $\begin{array}{l}\text { Become familiar with plant needs and how to select a good } \\
\text { garden site }\end{array}$ \\
\hline Rules 'n Tools & Establish garden rules and maintenance schedule \\
\hline Make Your Pick & $\begin{array}{l}\text { Select vegetables to grow based on the season and spacing } \\
\text { requirements }\end{array}$ \\
\hline The Pyramid & To use the Food Guide Pyramid in planning balanced meals \\
\hline Taste Test & To evaluate fruit based on color, texture, taste and smell \\
\hline Apple Surprise & $\begin{array}{l}\text { To taste test different varieties of apples and to make a healthy } \\
\text { fruit snack }\end{array}$ \\
\hline $\begin{array}{l}\text { Fruit and Veggie } \\
\text { Mania/Fruit and } \\
\text { Veggie Lab }\end{array}$ & $\begin{array}{l}\text { To gain a familiarity with characteristics of common and exotic } \\
\text { fruit and vegetables, and to review what parts of the plant } \\
\text { we eat }\end{array}$ \\
\hline Container Gardening & To learn how to successfully grow vegetables in containers \\
\hline
\end{tabular}

sures used at Texas A\&M University (J.M. Zajicek, personal communication), and the nutrition-centered lessons from Junior Master Gardener: Health and Nutrition from the Garden (Genzer et al., 2001).

Fruit and vegetable preferences were assessed with four fruit items and eight vegetable items considered common in Kansas. Fruit and vegetables were considered common if they were readily available at local grocery stores. This preference assessment was adapted from a similar fruit and vegetable preference instrument (Domel et al., 1993 ) in which a list of common fruit and vegetables is shown. Reported alpha coefficients for fruit preference ranged from 0.68 to 0.78 ; vegetable preference ranged from 0.68 to 0.76 (Domel et al., 1993). The students were asked to mark whether they "liked," "liked a little," "disliked," or "did not know" a particular fruit or vegetable on the list. Responses marked as "liked" were scored with 2 points, "liked a little" with 1 point, and "disliked" with 0 points; "did not know" responses were scored with 0 points and coded with a 9 for further analysis. Scores were then added to produce a total fruit preference and total vegetable preference score. Total possible fruit preference score was 8; total possible score for vegetable preference was 16 .

The self-efficacy instrument was adapted from previous research that measured self-efficacy in children (Domel et al., 1996). Two categories of self-efficacy were measured: gardening self-efficacy, and fruit and vegetable consumption self-efficacy. Self-efficacy is task-specific, so five task-specific items for each category were asked and then added to produce a total self-efficacy score for that particular category. For example, for gardening self-efficacy, students were asked how sure they were that they could do particular tasks associated with gardening (grow a small garden, water a garden so the plants can grow, etc.). Students responded on a three-response Likert scale whether they were "sure" they could do that particular task, "somewhat sure," or "not sure" whether they could perform that particular task. Responses were scored with a 2 for "sure," 1 for "somewhat sure," and 0 for "not sure." These scores were then added to produce a total self-efficacy score for that particular category. The 
total possible score for each category of self-efficacy was 10 .

The outcome expectations portion of the questionnaire was adapted from Domel et al. (1995) and included eight items: five items addressed gardening outcome expectations and three addressed fruit and vegetable consumption outcome expectations. These were assessed in a manner similar to the previous self-efficacy measurement in that students were to respond on a three-response Likert scale how true each particular statement was for them. The responses were either "sure" (yes, I agree this is true for me), "somewhat sure" (yes, I partly agree with this), and "not sure" (no, I definitely do not believe this is true for me). For example, with the statement "growing a vegetable garden will be fun," students were asked to mark the circle that they most agreed with for that statement. A response marked as "sure" was scored 2 points; "somewhat sure," I point; and "not sure," 0 points. To determine the total outcome expectations score for each category, all the items within a particular category were added and averaged. This produced a total possible score for gardening outcome expectations of 10 ; and the total possible score for fruit and vegetable consumption outcome expectations was 6.

DATA ANALYSIS. All data were analyzed using SPSS (version 11.5; SPSS Inc., Chicago). Instrument reliability for each measure, except nutrition knowledge, was calculated by using Cronbach's alpha coefficient. Based on children's nutrition and behavior change research, measures were considered reliable if the alpha coefficient was $\geq 0.55$ (D.A. Dzewaltowski, personal communication). Measures with acceptable alpha coefficients were then further analyzed for between- and within-group differences. Betweengroup analyses were conducted using independent $t$ tests and within-group analyses were conducted by using paired $t$ tests. In measures where the Cronbach's alpha values are low (fruit preference and fruit and vegetable consumption self-efficacy), only the means are reported in the tables because further analysis of these measures was not appropriate.

\section{Results and discussion}

Demographic information collected on all participants indicates that the groups were similar (Table 2 ). This study had a small sample size with no replication. Therefore, the results of this study cannot be generalized to populations outside of this study without caution.

Student attendance. Student attendance for this project was very high. Seventeen students regularly participated in the garden club, with the average attendance being 96\%. Thirteen of the students attended all garden club meetings and of the four students who had absences, no student missed more than two meetings.

Nutrition KNOWLEDGe. There were no significant differences between the experimental and control group mean scores at baseline or over the course of the program for nutrition knowledge (Table 3 ). The highest possible score was 10 and students in both groups scored a $70 \%$ or greater at baseline. These high baseline scores suggest that the students were already familiar with the nutrition topics that were addressed in this curriculum. Five questions on the nutrition knowledge portion of the test produced consistently high responses at baseline and end-program for both groups. Of these questions, the lowest score at baseline was $82 \%$ and end-program was $84 \%$ (Table 4).

Fruit and vegetable PREFERENCE. Mean fruit preference scores were high at baseline and end-program for both groups (Table 5). The experimental group indicated a preference for $89 \%$ of the fruits listed and the control group

Table 2. Demographic information collected from the experimental and control groups in the study of a 10-week after-school gardening and nutrition program for fourth grade students.

\begin{tabular}{lrr}
\hline $\begin{array}{l}\text { Demographic } \\
\text { data }^{\mathbf{z}}\end{array}$ & $\begin{array}{c}\text { Experimental } \\
(\mathbf{n}=\mathbf{1 7})\end{array}$ & $\begin{array}{c}\text { Control } \\
(\mathbf{n}=\mathbf{2 1})\end{array}$ \\
\hline Age & 11 & 12 \\
9 years & 6 & 9 \\
10 years & & \\
Gender & 10 & 9 \\
$\quad$ Female & 7 & 12 \\
$\quad$ Male & & \\
Ethnicity & 13 & 14 \\
$\quad$ Caucasian & 0 & 4 \\
African American & 1 & 1 \\
$\quad$ Hispanic & 1 & 1 \\
$\quad$ Asian & 2 & 1 \\
Other & & \\
Household & 13 & 16 \\
$\quad$ Mother and father & 1 & 1 \\
Parent and step-parent & 2 & 1 \\
Grandparent or guardian & 1 & 3 \\
Other &
\end{tabular}

${ }^{2}$ The experimental group participated in an eight-lesson (10-week) gardening and nutrition program. The control group did not participate in this program. Each group attended a different school.

Table 3. Mean nutrition knowledge baseline and end-program scores for the experimental and control groups in the study of a 10-week after-school gardening and nutrition program for fourth grade students.

\begin{tabular}{lccc}
\hline & \multicolumn{3}{c}{ Nutrition knowledge $(\mathbf{0}-\mathbf{1 0})^{\mathrm{z}}$} \\
\cline { 2 - 4 } Group (n) & $\mathbf{B}^{\mathrm{x}} \pm \mathrm{SE}$ & $\mathrm{E} \pm \mathrm{SE}$ & \multicolumn{1}{c}{ Significance } \\
\hline Experimental (17) & $7.53 \pm 0.34$ & $7.18 \pm 0.30$ & $\begin{array}{l}P=0.370 \\
(\mathrm{df}=16, \mathrm{t}=0.922)\end{array}$ \\
Control (21) & $7.05 \pm 0.29$ & $7.38 \pm 0.33$ & $\begin{array}{l}P=0.398 \\
(\mathrm{df}=20, \mathrm{t}=-0.863)\end{array}$ \\
Significance & $\begin{array}{l}P=0.287 \\
(\mathrm{df}=36, \mathrm{t}=1.081)\end{array}$ & $\begin{array}{l}P=0.659 \\
(\mathrm{df}=36, \mathrm{t}=0.445)\end{array}$ \\
&
\end{tabular}


Table 4. Nutrition knowledge questions that produced a high percentage of correct answers at baseline and end-program in the study of a 10-week after-school gardening and nutrition program for fourth grade students.

Question (answer) ${ }^{\mathrm{z}}$

What is the healthiest snack choice? (soda \& chips, milkshake \& fries, fruit juice and pretzels)

Which food listed below is considered a vegetable, but really is a fruit? (celery, carrot, lettuce, tomato, potato)

$\mathrm{T} / \mathrm{F}$ : A single food contains all the necessary vitamins and minerals a body needs. $(\mathbf{F})$

$\mathrm{T} / \mathrm{F}$ : The human body is composed of more than $70 \%$ water. $(\mathbf{T})$

T/F: You should eat cheese or drink milk at least three times a day. $(\mathbf{T})$

${ }^{\mathrm{z}}$ Correct answer is in bold.

y Percent correct are combined percentages from both groups $(\mathrm{n}=38)$. The Experimental group (17) participated in an eight-lesson (10-week) gardening and nutrition program. The control group (21) did not participate in this program. Each group attended a different school.

only preferred $55 \%$ of the vegetables at baseline. Both groups' mean score did increase from baseline to end-program, although not significantly. Previous work by the researchers had similar results in that there were no significant changes in vegetable preference during the program, and that overall participants preferred about $50 \%$ of

Baseline $^{\mathrm{y}}(\%)$ End-program (\%)

$100 \quad 97$

89

92

82

84

87

92

97

95

Table 5. Fruit and vegetable preference baseline and end-program scores for the experimental and control groups in the study of a 10-week after-school gardening and nutrition program for fourth grade students.

\begin{tabular}{|c|c|c|c|c|c|}
\hline \multirow[b]{2}{*}{ Group $^{x}(\mathbf{n})$} & \multicolumn{2}{|c|}{ Fruit preference $(0-8)^{\mathrm{z}}$} & \multicolumn{3}{|c|}{ Vegetable preference $(0-16)^{y}$} \\
\hline & $B^{w} \pm S E$ & $\mathrm{E} \pm \mathrm{SE}$ & $B \pm S E$ & $\mathrm{E} \pm \mathrm{SE}$ & Significance \\
\hline Experimental (17) & $7.18 \pm 0.31$ & $7.06 \pm 0.34$ & $10.94 \pm 0.92$ & $11.24 \pm 0.92$ & $\begin{array}{l}P=0.603 \\
(\mathrm{df}=16, \mathrm{t}=0.566)\end{array}$ \\
\hline Control (21) & $6.05 \pm 0.33$ & $6.05 \pm 0.33$ & $8.81 \pm 0.91$ & $9.05 \pm 0.97$ & $\begin{array}{l}P=0.489 \\
(d f=20, t=0.706\end{array}$ \\
\hline Significance & & & $\begin{array}{l}P=0.112 \\
(\mathrm{df}=36, \mathrm{t}=1.628)\end{array}$ & $\begin{array}{l}P=0.115 \\
(\mathrm{df}=36, \mathrm{t}=1.616)\end{array}$ & \\
\hline
\end{tabular}

${ }^{z}$ Total possible score for fruit preference was 8 . Due to low Cronbach's alpha, paired $t$ test was not done.

yTotal possible score for vegetable preference was 16 .

xThe experimental group participated in an eight-lesson (10-week) gardening and nutrition program. The control group did not participate in this program. Each group attended a different school.

"The letters " $\mathrm{B}$ " and "E" represent mean baseline and end-program scores \pm SE, respectively

Table 6. Gardening and fruit and vegetable (FV) consumption self-efficacy baseline and end-program scores for experimental and control groups in the study of a 10-week after-school gardening and nutrition program for fourth grade students.

\begin{tabular}{|c|c|c|c|c|c|}
\hline \multirow[b]{2}{*}{ Group $^{y}(\mathbf{n})$} & \multicolumn{3}{|c|}{ Gardening self-efficacy $(0-10)^{\mathrm{z}}$} & \multicolumn{2}{|c|}{ FV consumption self-efficacy $(0-10)^{z}$} \\
\hline & $B^{x} \pm S E$ & $\mathrm{E} \pm \mathrm{SE}$ & Significance & $\mathrm{B} \pm \mathrm{SE}$ & $\mathrm{E} \pm \mathrm{SE}$ \\
\hline Experimental (17) & $9.24 \pm 0.29$ & $9.06 \pm 0.29$ & $\begin{array}{l}P=0.605 \\
(\mathrm{df}=16, \mathrm{t}=0.527)\end{array}$ & $8.94 \pm 0.29$ & $9.06 \pm 0.26$ \\
\hline Control (21) & $6.95 \pm 0.61$ & $8.43 \pm 0.46$ & $\begin{array}{l}P=0.032^{*} \\
(\mathrm{df}=20, \mathrm{t}=-2.312)\end{array}$ & $8.33 \pm 0.33$ & $8.67 \pm 0.25$ \\
\hline
\end{tabular}

${ }^{2}$ Total possible self-efficacy score was 10 .

yhe experimental group participated in an eight-lesson (10-week) gardening and nutrition program. The control group did not participate in this program. Each group attended a different school.

"The letters "B" and "E" represent mean baseline and end-program scores \pm SE, respectively.

${ }^{*},{ }^{* *}$ Significant at $P \leq 0.05$ or 0.01 , respectively. 
Table 7. Gardening and fruit and vegetable (FV) consumption outcome expectations baseline and end-program scores for the experimental and control groups in the study of a 10 -week after-school gardening and nutrition program for fourth grade students.

\begin{tabular}{|c|c|c|c|c|c|c|}
\hline \multirow[b]{2}{*}{$\operatorname{Group}^{\mathrm{x}}(\mathrm{n})$} & \multicolumn{3}{|c|}{ Gardening outcome expectations $(0-10)^{\mathrm{z}}$} & \multicolumn{3}{|c|}{ FV consumption outcome expectations $(0-6)^{y}$} \\
\hline & $\mathrm{B}^{\mathrm{w}} \pm \mathrm{SE}$ & $\mathrm{E} \pm \mathrm{SE}$ & Significance & $\mathrm{B} \pm \mathrm{SE}$ & $\mathrm{E} \pm \mathrm{SE}$ & Significance \\
\hline Experimental (17) & $9.00 \pm 0.33$ & $8.59 \pm 0.31$ & $\begin{array}{l}P=0.110 \\
(d f=16 \\
t=1.692)\end{array}$ & $5.76 \pm 0.18$ & $5.24 \pm 0.27$ & $\begin{array}{l}P=0.034^{*} \\
(\mathrm{df}=16 \\
\mathrm{t}=2.314)\end{array}$ \\
\hline Control (21) & $6.48 \pm 0.55$ & $8.00 \pm 0.37$ & $\begin{array}{l}P=0.013^{* *} \\
(\mathrm{df}=20 \\
\mathrm{t}=-2.726)\end{array}$ & $5.29 \pm 0.24$ & $5.52 \pm 0.16$ & $\begin{array}{l}P=0.234 \\
(\mathrm{df}=20, \\
\mathrm{t}=-1.227)\end{array}$ \\
\hline Significance & $\begin{array}{l}P=0.000^{* * *} \\
(\mathrm{df}=32.05 \\
\mathrm{t}=3.949)\end{array}$ & $\begin{array}{l}P=0.240 \\
(\mathrm{df}=36 \\
\mathrm{t}=1.194)\end{array}$ & & $\begin{array}{l}P=0.136 \\
(d f=36 \\
t=1.525)\end{array}$ & $\begin{array}{l}P=0.341 \\
(\mathrm{df}=36 \\
\mathrm{t}=-0.964)\end{array}$ & \\
\hline
\end{tabular}

${ }^{2}$ Total possible score for gardening outcome expectations was 10 .

Total possible score for FV consumption outcome expectations was 6.

xThe experimental group participated in an eight-lesson (10-week) gardening and nutrition program. The control group did not participate in this program. Each group attended a different school.

"The letters " $B$ " and "E" represent mean baseline and end-program scores \pm SE, respectively

${ }^{*},{ }^{* *},{ }^{* * *}$ Significant at $P \leq 0.05,0.01$, or 0.001 , respectively.

vegetable preference. Furthermore, researchers should quantify gardening activities in existing programs as much as possible to determine, for example, if harvesting the vegetables grown in the garden has an effect on increasing students' preference for those vegetables.

In addition, during the 10 -week program, we taught one lesson each week for a total of $80 \mathrm{~min}$. Morris and Zidenberg-Cherr (2002) report teaching nine nutrition lessons every other week for 17 weeks, but do not report the total program time for each lesson. Lineberger and Zajicek (2000) required the teachers in their study to teach at least one lesson from each of the 10 units in the curriculum during the school year. The total amount of time the teachers and program leaders spent teaching these gardening and nutrition lessons is important information that is not reported.

Also, this study was an after-school program, and previous literature has been on gardening and nutrition programs that all took place within the school day. Programs within the school day differ greatly from those occurring after school. For example, teachers have certain expectations of children's behavior in the classroom that after-school program leaders may not have.

SElf-efricacy. The mean baseline scores for gardening self-efficacy of the experimental and control groups were significantly different; however, at end-program, scores of the two groups were not significantly different (Table 6). The experimental group maintained high self-efficacy for gardening at end-program; however, gardening self-efficacy scores of the control group increased significantly over the course of the program. Perhaps the students who were exposed to and learned proper gardening techniques acquired more skills over the course of the program, enabling them to maintain their high gardening self-efficacy during the program. The control group's increase in gardening self-efficacy might be explained by seasonal change. As spring weather progressed to summer, control students could have had more opportunities to be outside and garden in-between the two times when they were tested.

Mean scores for fruit and vegetable consumption self-efficacy for both groups increased (Table 6). Domel et al. (1996) stated that the students in their study reported being somewhere between "a little confident/sure" and "very confident/sure" that they could do the various tasks concerning eating more fruit and vegetables.

Outcome expectations. Mean baseline scores for gardening outcome expectations were significantly different between the groups $(P=0.000)$ (Table 7 ). This is likely a result of how the experimental group had been recruited. The students were asked to participate in the gardening club, and those who had an interest in gardening therefore could have had higher outcome expectations of gardening. Interestingly, over the course of the program the experimental group maintained high outcome expectations for gardening, while the score of the control group significantly increased $(P=0.013)$. These results parallel the gardening self-efficacy results for this study. The control group significantly increased its gardening self-efficacy and outcome expectations score while the experimental group maintained a high score for both. This can be explained by the relationship of self-efficacy and outcome expectations within SCT. Logically, as one increases their selfefficacy in a particular action, one has more predictions of what to expect the outcomes of such actions to be (Bandura, 1997).

Baseline and end-program scores between the two groups for fruit and vegetable consumption outcome expectations were not significantly different (maximum possible score of 6) (Table 7). The experimental group had higher fruit and vegetable consumption outcome expectations at baseline but significantly decreased those over the course of the program $(P=0.034)$. This could possibly be the result of how ripe some fruits were when served at two of the garden club sessions. Even though the questionnaire assessed health-related expectations rather than taste, perhaps the students could have remembered the taste of those particular fruits and that memory could have influenced their response to these questions during the end-program assessment. Overall, students in both groups had high outcome expectations for eating fruit and vegetables.

\section{Conclusions}

Baseline nutrition knowledge scores of the experimental and control 
groups were very high. These high scores suggest that school nutrition lessons and programs such as 5-A-Day (Perry et al., 1998) and Team Nutrition (Levine et al., 2002) are successful at teaching nutrition knowledge. However, knowledge only creates the precondition for change; additional self-influences are needed to overcome the barriers to adopting new lifestyle habits (Bandura, 1997). Increasing preference for fruits and vegetables is a very important step to increasing fruit and vegetable consumption in this cohort (Baxter and Thompson, 2002; Domel et al., 1996). This study did not increase vegetable preference, which contradicts reported research (Lineberger and Zajicek, 2000; Morris and Zidenberg-Cherr, 2002). In addition to sample size, differences in the methodology of this study compared with previous research were found. Future research should determine whether the program length and delivery (in school vs. after school) of gardening and nutrition programs are more critical, or if certain aspects of the program (instruction, planting, gardening maintenance, harvesting, and season) are more critical in helping to increase children's vegetable preference. In addition, this study supports the use of SCT in gardening and nutrition research through the use of preference, self-efficacy and outcome expectation instruments.

\section{Literature cited}

Bandura, A. 1997. Self-efficacy: The exercise of control. Freeman, New York.

Bandura, A. 2004. Health promotion by social cognitive means. Health Educ. Behavior 31(2):143-164.

Baranowski, T., S. Domel, R. Gould, J. Baranowski, S. Leonard, F. Treiber, and R. Mullis. 1993. Increasing fruit and vegetable consumption among 4 th and 5 th grade students: Results from focus groups using reciprocal determinism. J. Nutr. Educ. 12(3):185-190.

Baranowski, T., C.L. Perry, and G.S. Parcel. 1997. How individuals, environments, and health behavior interact: Social cognitive theory, p. 153-178. In: K. Glanz, F.M. Lewis, and B.K. Rimer (eds.). Health behavior and health education. Wiley, San Francisco.

Baxter, S.D. and W.O. Thompson. 2002. Fourth-grade children's consumption of fruit and vegetable items available as part of school lunches is closely related to preferences. J. Nutr. Educ. Behavior 34(3):166-171.

Canaris, I. 1995. Growing foods for growing minds: Integrating gardening and nutrition education into the total curriculum. Children's Environ. 12(2):264-270.

Cason, K.L. 1999. Children are "growing healthy" in South Carolina. J. Nutr. Educ. 31(4):235A.

Cook, A.J. and J.E. Friday. 2004. Pyramid servings intakes in the United States 1999-2002, 1 day. 15 July 2005 . <http:// www.ba.ars.usda.gov/cnrg/services/ts_3$0 . \mathrm{pdf}>$.

Domel, S., T. Baranowski, H. Davis, S. Leonard, P. Riley, and J. Baranowski. 1993. Measuring fruit and vegetable preferences among 4 th and 5 th grade students. Preventative Medicine 22:866-879.

Domel, S.B., T. Baranowski, H.C. Davis, W.O. Thompson, S.B. Leonard, and J. Baranowski. 1995. A measure of outcome expectations for fruit and vegetable consumption among fourth and fifth grade children: Reliability and validity. Health Educ. Res. 10(1):65-72.

Domel, S.B., W.O. Thompson, H.C. Davis, T. Baranowski, S.B. Leonard, and J. Baranowski. 1996. Psychosocial predictors of fruit and vegetable consumption among elementary school children. Health Educ. Res. 11(3):299-308.

Family Nutrition Program. 2003. Youth pre-evaluation grades 3-6. 4 May 2005. <http://www.humec.ksu.edu/fnp/evaluation/3-6/preevaluation.pdf>.

Genzer S., R. Seagraves, J. Anding, L. Whittlesey, O. Aguilar, G. Graves, C. Klemmer, S. Koch, S. Lineberger, D. Reed, S. Robinson, C. Sebesta, P.V. Laanen, A. Wagner, C. Walton-Robinson, D.F. Welsh, D. Woodson, and J. Zajicek. 2001. Health and nutrition from the garden. Junior Master Gardener, Golden Ray Ser., Newman Publ., Bryan, Texas.

Kirby, S.D., T. Baranowski, K.D. Reynolds, G. Taylor, and D. Binkley. 1995. Children's fruit and vegetable intake: Socioeconomic, adult-child, regional, and urban-rural influences. J. Nutr. Educ. 27(5):261-269.

Levine, E., C. Olander, C. Lefebvre, P. Cusick, L. Biesiadecki, and D. McGoldrick. 2002. The team nutrition pilot study: Lessons learned from implementing a comprehensive school-based intervention. J. Nutr. Educ. Behavior 34(2):109-116.

Lineberger, S.E. and J.M. Zajicek. 2000. School gardens: Can a hands-on teaching tool affect students' attitudes and behaviors regarding fruit and vegetables? HortTechnology 10(3):593-597.
Lytle, L. and C. Achterberg. 1995. Changing the diet of America's children: What works and why? J. Nutr. Educ. 27(5):250-260.

Morris, J.L., K.L. Koumjian, M. Briggs, and S. Zidenberg-Cherr. 2002. Nutrition to grow on: A garden-enhanced nutrition education curriculum for upper-elementary schoolchildren. J. Nutr. Educ. Behavior 34(3):175-176.

Morris, J.L., A. Neustadter, and S. Zidenberg-Cherr. 2001. First-grade gardeners more likely to taste vegetables. Calif. Agr. 55(1):43-46.

Morris, J.L. and S. Zidenberg-Cherr. 2002. Garden-enhanced nutrition curriculum improves fourth-grade school children's knowledge of nutrition and preferences for some vegetables. J. Amer. Dietetic Assn. 102(1):91-93.

Nicklas, T. and R. Johnson. 2004. Position of the American Diabetic Association: Dietary guidance for healthy children ages 2 to 11 years. J. Amer. Dietetic Assn. 104(4):660-667.

Perry, C.L., D.B. Bishop, G. Taylor, M. Davis, M. Story, C. Gray, S.C. Bishop, R. W. Mays, L.A. Lytle, and L. Harnack. 2004. A randomized school trial of environmental strategies to encourage fruit and vegetable consumption among children. Health Educ. Behavior 31(1):65-76.

Perry, C.L., D.B. Bishop, G. Taylor, D.M. Murray, R.W. Mays, B.S. Dudovitz, M. Smith, and M. Story. 1998. Changing fruit and vegetable consumption among children: The 5-a-day power plus program in St. Paul, Minnesota. Amer. J. Public Health 88(4):603-609.

Poston, S.A., C.A. Shoemaker, and D.A. Dzewaltowski. 2005. A comparison of a gardening and nutrition program with a standard nutrition program in an out-of-school setting. HortTechnology 15(3):463-467.

Reniscow, K., M. Smith, T. Baranowski, J. Baranowski, R. Vaughan, and M. Davis. 1998. 2-year tracking of children's fruit and vegetable intake. J. Amer. Dietetic Assn. 98(7):785-789.

Reynolds, K.D., A.W. Hinton, R.M. Shewchuk, and C.A. Hickey. 1999. Social cognitive model of fruit and vegetable consumption in elementary school children. J. Nutr. Educ. 31(1):23-29.

Ryan, G.J. and D.A. Dzewaltowski. 2002. Comparing the relationships between different types of self-efficacy and physical activity in youth. Health Educ. Behavior 29(4):491-504.

U.S. Department of Agriculture. 2005. MyPyramid.gov. 4 May 2005. <http:// www.mypyramid.gov/>. 